\title{
Omega 3 fatty acids and cognitive health in older people
}

\author{
Alan D. Dangour ${ }^{1 *}$, Valentina A. Andreeva ${ }^{2}$, Emma Sydenham $^{1}$ and Ricardo Uauy ${ }^{1,3}$ \\ ${ }^{1}$ Department of Nutrition and Public Health Intervention Research, Faculty of Epidemiology and Population Health, London \\ School of Hygiene \& Tropical Medicine, Keppel Street, London WC1E 7HT, UK \\ ${ }^{2}$ Nutritional Epidemiology Research Unit, University of Paris XIII, Bobigny, France \\ ${ }^{3}$ Department of Public Health Nutrition, Institute of Nutrition and Food Technology (INTA), University of Chile, \\ Santiago, Chile
}

\begin{abstract}
Oily fish and other sources of long-chain n-3 polyunsaturated fatty acids ( $\mathrm{n}-3$ LCPs) have been proposed as protective against dementia and age related cognitive impairment. The basic mechanisms underlying these proposed benefits have been postulated and experimental studies supporting the plausibility of the putative effects have been published. Observational epidemiological and case control studies also largely support a protective role of fish consumption on cognitive function with advancing age, albeit with important unexplained heterogeneity in findings. In this review we report the findings of the latest Cochrane review on the benefits of n-3 LCP supplementation on cognitive function among cognitively healthy older people and expand the review by including trials conducted with individuals with prevalent poor cognitive function or dementia. We identified seven relevant trials, four among cognitively healthy older people, and three among individuals with pre-existing cognitive decline or dementia, and overall conclude that there is no evidence to support the routine use of n-3 LCPs supplements for the prevention, or amelioration, of cognitive decline in later life. We identified several challenges in the design of intervention studies for the prevention of dementia and cognitive decline in older people that require careful consideration especially in recruitment and retention in long-term trials. Whether the lack of agreement in findings from mechanistic and observational data and from intervention studies reflects a real absence of benefit on cognitive function from n-3 LCP supplementation, or whether it reflects intrinsic limitations in the design of published studies remains open to question.
\end{abstract}

Key words: Older people: Cognitive health: Dementia: $\mathbf{n}-3$ fatty acids

Numerous reviews of findings from animal research as well as biological, clinical and epidemiological data underscore a protective role of dietary intake of $n-3$ (or omega-3) long-chain polyunsaturated fatty acids (n-3 LCPs) on dementia, including Alzheimer's disease (AD). Various mechanisms of action have been proposed including improvement of cerebral blood flow, maintenance of the structural integrity of neuronal membranes, and reduction in amyloid- $\beta$ pathology ${ }^{(1-7)}$. The balance of evidence from prospective studies suggests that $n-3$ LCPs may have a greater role in slowing or delaying cognitive decline among healthy older people than in the treatment of individuals with dementia ${ }^{(2,3,6,7)}$. The brain is particularly rich in n-3 LCPs and several mechanisms have been postulated for their potential protective actions. First, docosahexaenoic acid (DHA) is a component of membrane phospholipids in the brain and adequate n-3 LCP status contributes to specific neural membrane structural properties and functions including ion transport, signal transduction, synapsis formation, neurotransmitter release and reuptake. DHA also contributes to sequestering free radicals and preventing amplification of oxidative damage. Secondly, eicosanoids and docosanoids produced by cyclo- and lipo-oxygenase action on long-chain polyunsaturated fatty acids act as cellular mediators of inflammation, allergy and immunity, oxidative damage, vascular responses and thrombosis and may thereby influence risk especially of vascular dementia ${ }^{(8)}$.

Evidence from cross-sectional analyses involving dietary fish and/or supplemental n-3 LCP intake, as well as findings based on plasma eicosapentaenoic acid (EPA) and DHA concentrations are equivocal. For example, some epidemiological studies document dose-response protective asssociations of n-3 LCPs on the cognitive performance of older individuals in different countries ${ }^{(9,10)}$, with the associations applying to various cognitive domains ${ }^{(10)}$, whereas other similarly designed studies report no associations in adjusted models ${ }^{(11,12)}$. Regarding plasma n-3 LCP concentrations, case-control ${ }^{(13)}$ and prospective studies with older individuals free of dementia at baseline report significant inverse associations between

Abbreviations: AD, Alzheimer's disease; ALA, alpha-linolenic acid; BIS, Barratt Impulsiveness scale; CVLT, California Verbal Learning Test; DHA, docosahexaenoic acid; EPA, eicosapentaenoic acid; MMSE, Mini-Mental State Examination; n-3 LCPs, n-3 long-chain polyunsaturated fatty acids. 
the concentrations of these nutrients and risk of cognitive decline or incident dementia ${ }^{(14,15)}$. However, other studies have documented elevated EPA concentrations among cognitively impaired older individuals, and elevated DHA, n-3 fatty acids, and total long-chain polyunsaturated fatty acids concentrations have been observed among individuals with dementia $^{(16)}$

Population-based longitudinal analyses of data from older individuals who were cognitively healthy at baseline generally show an inverse association between fish consumption and incident dementia ${ }^{(17-19)}$, albeit with some exceptions ${ }^{(12,20)}$. Somewhat less consistency exists among the research findings regarding the types of $\mathrm{n}-3 \mathrm{LCP}$ s purporting the strongest benefit. Some prospective epidemiological studies show both EPA and DHA to be protective against cognitive decline ${ }^{(19)}$, whereas others report associations either with $\mathrm{DHA}^{(18)}$ or $\mathrm{EPA}^{(21)}$.

A comprehensive review of 27 prospective studies of fish or n-3 LCPs in diet or blood, and 9 cross-sectional studies of n-3 LCPs in plasma, erythrocytes, or in the diet suggested that the lack of consistency in the findings could be attributed to disparate study designs and populations, inadequate statistical adjustment, and differences in predictor/outcome assessment methodology ${ }^{(3)}$. Authors have also highlighted that fish intake is not equivalent to n-3 LCP intake and that the genetic heterogeneity among different populations with respect to both n-3 fatty acids metabolism and dementia susceptibility might weaken the benefits of these nutrients ${ }^{(2)}$

A Cochrane review of the evidence from randomised controlled trials found no trials published before October 2005 investigating the effects of $n-3$ polyunsaturated fatty acid supplementation on cognitive function among cognitively healthy older people ${ }^{(22)}$. We here present findings from the recently updated Cochrane review ${ }^{(23)}$ of the effect of $n-3$ polyunsaturated fatty acid supplementation on the prevention of dementia and cognitive decline among cognitively healthy older people and expand the scope of the review to include randomised controlled trials conducted among individuals with prevalent poor cognitive function or dementia.

\section{Methods}

For a Cochrane review update ${ }^{(23)}$, the major healthcare databases (Medline, Embase, Cinahl, Psycinfo and Lilacs) and trial registers (International Standard Randomised Controlled Trial Number, ClinicalTrials.gov and The Cochrane Library's Central Register of Controlled Trials) were systematically searched up to April 2012. Search terms included variants and combinations of: fatty acids, omega-3, polyunsaturated fatty acid, unsaturated fatty acid, essential fatty acid, eicosapentaenoic acid, docosahexaenoic acid, docosapentaenoic acid, alpha-linolenic acid, fish oil, n-3 fatty acid, long chain fatty acids, primrose oil, linseed oil, oily fish, flaxseed oil, randomized controlled trial, controlled clinical trial, healthy old or elderly or aged or senior, healthy persons, cognition, dementia.

For the Cochrane review update ${ }^{(23)}$, randomised controlled trials involving individuals over 60 years of age were included if they also had the following characteristics. First, they prescreened participants for dementia and excluded individuals with pre-existing dementia. Second, they pre-screened participants for cognitive impairments and excluded individuals with pre-existing cognitive impairment. Third, the intervention period was a minimum duration of 26 weeks (180 days).

In this review we expand the inclusion criteria for studies and participants to include randomised controlled trials that did not screen or exclude individuals with possible cognitive decline or with existing cognitive impairment or dementia. We chose to include any n-3 polyunsaturated fatty acid intervention (including mixtures of $n-3$ fatty acids) that involved dietary supplementation or provided meals, versus placebo or usual diet. Our primary outcome of interest was incidence of dementia, our secondary outcome was cognitive decline defined as change in a relevant cognitive function over the intervention period.

\section{Results}

Our systematic search process identified 7 relevant studies for this review (Table 1). Three studies (included in the Cochrane review) enrolled only cognitively healthy older people $e^{(24-26)}$ one study enrolled apparently cognitively normal older people but did not screen for cognitive function at baseline ${ }^{(27)}$, one study enrolled participants with age-related cognitive decline ${ }^{(28)}$ and two studies enrolled participants with mild to moderate $\mathrm{AD}^{(29,30)}$. All studies were conducted in highincome countries, sample sizes ranged from 204 to 4837 and study duration ranged from 24 weeks to 4 years. Of the identified trials, six provided interventions as daily capsules containing varying mixtures of EPA and DHA with overall doses up to $2 \mathrm{~g}$ per day. One trial provided fortified margarines containing EPA, DHA and alpha-linolenic acid (ALA) ${ }^{(25)}$. None of the identified trials provided information on the incidence of dementia. Change in cognitive outcome was assessed using a variety of measures (Table 2) and study findings are presented below in narrative format.

\section{Trials in cognitively healthy older populations}

In a study from the Netherlands, a total of 302 cognitively healthy older people aged $\geq 65$ years were randomised into a low-dose treatment group ( $400 \mathrm{mg}$ EPA + DHA daily), a high-dose treatment group (1800 mg EPA + DHA daily), or placebo (sunflower oil) for 26 weeks. Cognitive function was evaluated at baseline and follow-up with a large battery of cognitive tests assessing memory, executive function, attention and sensorimotor speed. An analysis of variance showed no significant differences between the groups in cognitive tests scores at the end of the study ${ }^{(26)}$.

In the OPAL study a total of 867 cognitively healthy adults aged 70-79 years were randomised into an active group (200 mg EPA + $500 \mathrm{mg}$ DHA daily) or placebo (olive oil) for 24 months. Cognitive function was evaluated at baseline and follow-up with a battery of cognitive tests, including the California Verbal Learning Test (CVLT) as the primary outcome. A total of 748 participants completed the study. Intention-to-treat analysis of covariance models showed no change over the course of the intervention in CVLT or any secondary cognitive 
outcomes $^{(24)}$, secondary analysis revealed interaction between specific genetic polymorphisms in fatty-acid desaturase genes and lipid transport proteins and the response to the intervention (in preparation).

A secondary outcome paper from the Alpha Omega Trial $^{(31)}$, reported the impact of four margarine varieties (daily intake of margarine supplemented with $400 \mathrm{mg}$ $\mathrm{EPA}+\mathrm{DHA}$ in a 3:2 ratio, margarine supplemented with $2 \mathrm{~g}$ ALA, margarine supplemented with $400 \mathrm{mg}$ EPA + DHA and $2 \mathrm{~g}$ ALA, or placebo margarine) for 40 months on 4837 older people aged 60-80 years with a history of myocardial infarction. Cognitive function data were collected on 2911 of the randomised individuals. Rates of change in cognitive function, assessed using the Mini-Mental State Examination (MMSE), did not differ between trial arms over the course of the study ${ }^{(25)}$.

The SU.FOL.OM3 trial randomised 2501 individuals with a history of cardiovascular disease. Of the randomised individuals, 1748 had complete cognitive assessment data, 858 of whom were aged $>60$ years and are included in this review. There was no formal screening of participants for cognitive function at the start of the study. Participants were randomised in a $2 \times 2$ factorial design to one of four groups: $0.56 \mathrm{gm}$ folate $+3 \mathrm{mg}$ vitamin $\mathrm{B} 6+0.02 \mathrm{mg}$ vitamin $\mathrm{B} 12$; or $600 \mathrm{mg} \mathrm{EPA}+\mathrm{DHA}$ in a $2: 1$ ratio; or $\mathrm{B}$ vitamins and $\mathrm{n}-3$ LCPs combined; or placebo (liquid paraffin + fish oil). Cognitive function after 4 years of supplementation was assessed with the French version of the modified Telephone Interview for Cognitive Status. Analysis of covariance and multiple logistic regression showed no significant effects of group assignment on cognitive function ${ }^{(27)}$.

\section{Trials among older populations with evidence of cognitive impairment}

In a study from Sweden, 204 adults (mean age $=74 \mathrm{y}$ ) with mild to moderate $\mathrm{AD}$ were randomised to an active group $(1700 \mathrm{mg}$ $\mathrm{DHA}+600 \mathrm{mg}$ EPA daily) or placebo (corn oil including $0.6 \mathrm{~g}$ linoleic acid) for 6 months. After 6 months, all participants received the n-3 LCP supplementation for an additional 6 months. Cognitive function was assessed with the MMSE, the cognitive subscale of the Alzheimer's Disease Assessment Scale and the Clinical Dementia Rating scale. A total of 174 participants completed the trial. At 6 months, repeated-measures analysis of variance showed that the decline in cognitive functions did not differ between the groups. However, in a subgroup ( $n=32$ ) with very mild cognitive dysfunction at baseline, statistically significant positive effects of the supplementation on MMSE scores were observed ${ }^{(29)}$.

In the MIDAS trial, 485 individuals aged $\geq 55$ years with defined age-related cognitive decline were randomised into an active group (900 mg DHA daily) or placebo (corn oil + soy oil) for 24 weeks. The primary outcome was the CANTAB Paired Associate Learning (PAL) and adjusted

Table 1. General characteristics of randomised controlled trials included in review

\begin{tabular}{|c|c|c|c|}
\hline First author, study location & Study population & Interventions & Duration (months) \\
\hline Andreeva, France ${ }^{(27)}$ & Subsample of 858 adults aged $>60$ years & $\begin{array}{l}\text { Active } \\
600 \mathrm{mg} \text { EPA + DHA daily } \\
\text { Placebo } \\
\text { liquid paraffin + fish oil + B vitamins }\end{array}$ & 48 \\
\hline Dangour, England and Wales ${ }^{(24)}$ & $\begin{array}{l}867 \text { adults aged } 70-79 \text { years. } \\
\text { Key exclusion: poor cognitive health } \\
\text { (Mini-Mental State } \\
\text { Examination }[\text { MMSE] }<24 \text { ) }\end{array}$ & $\begin{array}{l}\text { Active } \\
200 \mathrm{mg} \text { EPA }+500 \mathrm{mg} \text { DHA daily } \\
\text { Placebo } \\
\text { olive oil }\end{array}$ & 24 \\
\hline Freund-Levi, Sweden ${ }^{(29)}$ & $\begin{array}{l}204 \text { adults with mean age } 74 \text { years } \\
\text { and mild to moderate Alzheimer's } \\
\text { Disease (MMSE } \geq 15 \text { ) }\end{array}$ & $\begin{array}{l}\text { Active } \\
1.7 \mathrm{~g} \text { DHA }+0.6 \mathrm{~g} \text { EPA daily } \\
\text { Placebo } \\
\text { corn oil including } 0.6 \mathrm{~g} \text { linoleic acid }\end{array}$ & 6 \\
\hline Geleijnse, The Netherlands ${ }^{(25)}$ & $\begin{array}{l}2911 \text { adults aged } 60-80 \text { years with } \\
\text { history of myocardial infarction. } \\
\text { Key exclusion: poor cognitive health } \\
\text { (MMSE }<21 \text { ) }\end{array}$ & $\begin{array}{l}\text { Active } \\
\text { margarines containing } \\
\text { a. } 400 \mathrm{mg} \text { EPA/DHA daily } \\
\text { b. } 2 \mathrm{~g} \text { ALA daily } \\
\text { c. } 400 \mathrm{mg} \text { EPA/DHA }+2 \mathrm{~g} \mathrm{ALA} \text { daily } \\
\text { Placebo } \\
\text { Margarine }\end{array}$ & 40 \\
\hline Quinn, USA ${ }^{(30)}$ & $\begin{array}{l}402 \text { adults with mean age } 76 \text { years } \\
\text { and mild to moderate Alzheimer's } \\
\text { Disease (MMSE }=14-26 \text { ) }\end{array}$ & $\begin{array}{l}\text { Active } \\
2 \mathrm{~g} \text { algal DHA daily } \\
\text { Placebo } \\
\text { corn or soy oil }\end{array}$ & 18 \\
\hline Van de Rest, The Netherlands ${ }^{(26)}$ & $\begin{array}{l}302 \text { adults aged } \geq 65 \text { years. } \\
\text { Key exclusion: poor cognitive } \\
\text { health (MMSE }<21 \text { ) }\end{array}$ & $\begin{array}{l}\text { Active } \\
\text { a. } 1800 \mathrm{mg} \text { EPA + DHA daily } \\
\text { b. } 400 \mathrm{mg} \mathrm{EPA}+\mathrm{DHA} \text { daily } \\
\text { Placebo } \\
\text { high-oleic sunflower oil }\end{array}$ & 6 \\
\hline Yurko-Mauro, USA ${ }^{(28)}$ & $\begin{array}{l}485 \text { adults aged } \geq 55 \text { years with age-related } \\
\text { cognitive decline and } \leq 28 \text { on logical memory } \\
\text { immediate recall or } \leq 15 \text { on delayed } \\
\text { recall, and MMSE } \geq 26\end{array}$ & $\begin{array}{l}\text { Active } \\
\text { 900mg DHA daily } \\
\text { Placebo } \\
\text { corn oil + soy oil }\end{array}$ & 6 \\
\hline
\end{tabular}


Table 2. Primary cognitive test results from randomised controlled trials included in review

\begin{tabular}{|c|c|c|c|c|}
\hline First author & Intention to treat sample & Primary cognitive outcome measure & Baseline score ${ }^{a}$ & Final score $^{a}$ \\
\hline Andreeva et al. ${ }^{(27)}$ & $\begin{array}{l}\text { Active } \\
420 \\
\text { Placebo } \\
438\end{array}$ & $\begin{array}{l}\text { Telephone Interview for Cognitive Status, } \\
\text { modified French version }\end{array}$ & Not collected & $\begin{array}{l}\text { Active } \\
27 \cdot 2(4 \cdot 9) \\
\text { Placebo } \\
27 \cdot 3(5 \cdot 1)\end{array}$ \\
\hline \multirow[t]{4}{*}{ Dangour et al..$^{(24)}$} & Active & California Verbal Learning & Active & Active \\
\hline & 375 & Test immediate recall (sum of 3 trials) & $24 \cdot 1(6 \cdot 0)$ & $24 \cdot 1(6 \cdot 7)$ \\
\hline & Placebo & & Placebo & Placebo \\
\hline & 369 & & $23.9(5 \cdot 7)$ & $24.4(6.4)$ \\
\hline \multirow[t]{6}{*}{ Freund-Levi et al. ${ }^{(29)}$} & Active & Mini-Mental State & Active & Active \\
\hline & 103 & Examination (MMSE) & MMSE: $23.6(22 \cdot 8,24 \cdot 4)^{\mathrm{b}}$ & MMSE: $22 \cdot 1(21 \cdot 1,23 \cdot 1)^{\mathrm{b}}$ \\
\hline & Placebo & Alzheimer's Disease & ADAS-Cog: $25 \cdot 7(23 \cdot 6,27 \cdot 8)^{b}$ & ADAS-Cog: $31.2(28.3,34.2)^{\mathrm{b}}$ \\
\hline & 101 & Assessment Scale (ADAS-Cog) & Placebo & Placebo \\
\hline & & & MMSE: $23 \cdot 2(22 \cdot 4,24 \cdot 0)^{\mathrm{b}}$ & MMSE: $21 \cdot 9(20 \cdot 8,22 \cdot 9)^{b}$ \\
\hline & & & ADAS-Cog: $27 \cdot 2(25 \cdot 1,29 \cdot 4)^{b}$ & ADAS-Cog: $32.8(29.8,35.9)^{\mathrm{b}}$ \\
\hline \multirow[t]{5}{*}{ Geleijnse et al. ${ }^{(25)}$} & Active & MMSE & Active and placebo & Active \\
\hline & 1,240 & & $28 \cdot 3(1 \cdot 6)$ & a. Change: $-0.78(2.32)$ \\
\hline & Placebo & & & b. Change: $-0.67(2.24)$ \\
\hline & 1,282 & & & c. Change: $-0.53(2.07)$ \\
\hline & & & & $\begin{array}{l}\text { Placebo } \\
\text { Change - } 0.71(2.36)\end{array}$ \\
\hline \multirow{6}{*}{ Quinn et al. ${ }^{(30)}$} & Active & ADAS-Cog & Active & 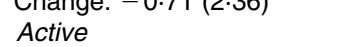 \\
\hline & 238 & Clinical Dementia Rating & ADAS-Cog: 23.77 (8.9) & ADAS-Cog change: 7.98 \\
\hline & Placebo & (CDR) sum of boxes & CDR: $5.61(2.62)$ & CDR change: 2.87 \\
\hline & 164 & & Placebo & Placebo \\
\hline & & & ADAS-Cog: $23.96(9.2)$ & ADAS-Cog change: 8.27 \\
\hline & & & CDR: $5.77(2.61)$ & CDR change: 2.93 \\
\hline \multirow[t]{6}{*}{ Van de Rest et al. ${ }^{(26)}$} & Active high dose & Word Learning Test (WLT) & Active high dose & Active high dose \\
\hline & & immediate recall (sum of 5 trials) & $39 \cdot 3(8 \cdot 8)$ & $44.9(9.9)$ \\
\hline & Active low dose & & Active low dose & Active low dose \\
\hline & 100 & & $40.8(8.6)$ & $46 \cdot 1(10 \cdot 1)$ \\
\hline & Placebo & & Placebo & Placebo \\
\hline & 106 & & $39.6(9 \cdot 7)$ & $44.8(9.4)$ \\
\hline \multirow[t]{4}{*}{ Yurko-Mauro et al..$^{(28)}$} & Active & CANTAB Paired Associate & Active & Active \\
\hline & 242 & Learning $(\mathrm{PAL})$ test & $13.4(11.6)$ & $8.8(9.9)$ \\
\hline & Placebo & & Placebo & Placebo \\
\hline & 243 & & $12 \cdot 1(10 \cdot 9)$ & $9.7(10.4)$ \\
\hline
\end{tabular}

a Values are mean (SD) unless stated.

b Mean ( $95 \%$ confidence interval). 
ANCOVA showed that treatment was associated with significantly fewer PAL 6 pattern stage errors ${ }^{(28)}$

Finally, the Alzheimer's Disease Cooperative Study randomised 402 individuals (mean age $=76 \mathrm{y}$ ) with mild to moderate AD into an active group (2000 mg DHA daily) or placebo (corn or soy oil) for 18 months. Cognitive function was assessed with the cognitive subscale of the Alzheimer's Disease Assessment Scale and the Clinical Dementia Rating sum of boxes. A total of 295 participants completed the trial and analysis did not identify any evidence that compared to the placebo, DHA slowed the rate of cognitive decline in these participants ${ }^{(30)}$.

\section{Discussion}

Several mechanisms have been postulated for the possible protective role of $n-3$ LCPs in cognitive decline and dementia. Experimental animal studies using a mouse model of AD have shown that dietary DHA deficiency induces a decline in DHA content of the frontal cortex which is significantly associated with loss of dendritic spine formation, increases oxidative damage and affects the hippocampus impairing memory acquisition, while supplementation with DHA increases n-3 LCP content of the brain, protects against adverse biochemical effects of deficiency, and results in improved cognitive performance ${ }^{(32)}$. DHA also modulates expression of genes related to neurogenesis ${ }^{(33)}$ and is directly involved in protection of the ageing brain from hypoxic injury through docosanoid-related mechanisms $^{(34,35)}$.

The recent United Nations Food and Agriculture Organisation consultation on fats and fatty acids in human nutrition recommended an n-3 LCP (EPA + DHA) intake for adults of $250 \mathrm{mg}$ per day and stated that this may contribute to the prevention of cardiovascular disease ${ }^{(36)}$. The significant role of n-3 LCPs for brain health was acknowledged but no recommendations were established for older people based on this role because the data on specific functional outcomes were considered insufficient. The average dietary intake of preformed DHA in European adults consuming omnivorous diets is about $150-200 \mathrm{mg}$ per day although intake levels in much of the rest of the world are far lower ${ }^{(37)}$.

For this review we identified seven trials that investigated the effect of n-3 LCP supplementation on cognitive function in older people. Four of these trials were among cognitively healthy (or presumptively cognitive healthy) older people ${ }^{(24-27)}$, and none of these trials identified any benefit from n-3 LCP supplementation. A further three trials enrolled older people with cognitive function impairments ranging from defined age-related cognitive decline to moderate AD. One of these three trials identified some evidence of a benefit from DHA supplementation ${ }^{(28)}$, the other two trials did not support this finding ${ }^{(29,30)}$. Overall, the evidence from trials of n-3 LCP supplementation among cognitively healthy and cognitively impaired older people does not support the use of n-3 LCPs for the prevention of cognitive decline.

The strength of the epidemiologic associations and the proposed mechanisms underlying the effects of n-3 LCPs on brain function are increasing, and yet of seven trials included in our review, only one identified any potential benefits from n-3 LCP supplementation on cognitive function. This discrepancy between epidemiological associations and trial evidence is not unique to $\mathrm{n}-3 \mathrm{LCPs}^{(38)}$ although there may also be some unique challenges in the design of long-term intervention studies for the prevention of dementia and cognitive decline in older people.

From the standpoint of determining the primary health effectiveness of interventions, a key concern relates to the recruitment of samples of older people that match the health and demographic characteristics of the target population $^{(39)}$. Recruitment procedures (including the use of extensive exclusion criteria) favour the selection of healthier participants, and participants who are more motivated and adherent to instructions tend to be healthier, consume a better diet and are more active. Physical activity and food consumption patterns may have an effect on disease progression that is separate from the effect of the intervention under investigation.

Retention of participants in long-term studies of cognitive function is also a concern since individuals who drop out of trials frequently have different demographic and health characteristics from those who remain active until the end of the trial. In the four trials that recruited cognitive healthy (or presumptively cognitive healthy) adults, the percentage of participants with data available for the final trial analyses varied from between $62 \%$ in a trial of 40 month duration ${ }^{(25)}$ to $99 \%$ in a trial of 6 month duration ${ }^{(26)}$. In the OPAL trial ( 24 month duration), retention was $86 \%$, and those individuals who withdrew had poorer cognitive function at the start of the study than those who remained in the study ${ }^{(24)}$. Similarly, in the SU.FOL.OM3 trial (48 month duration), retention was $75 \%$ and individuals who completed the trial had higher EPA and DHA concentrations and had slightly higher verbal fluency at baseline ${ }^{(27)}$. As expected, longer trials had lower overall retention and the evidence also suggests that those participants who drop out of trials are potentially exactly those who might benefit most from n-3 LCP supplementation.

From the perspective of identifying a suitable intervention to maintain cognitive function into later life, the current evidence base is disappointing. Whether this lack of evidence results from insufficient thought into designing studies of appropriate size and duration, or whether it relates to the selection of study populations who may benefit most from n-3 supplementation, such as those with low n-3 LCP status at study entry, or finally whether it suggests that despite the epidemiological and mechanistic evidence n-3 LCP supplementation does not affect cognitive function, remains open to question.

\section{Acknowledgements}

ADD and RU defined the scope of the review. VAA extracted trial data and wrote first drafts of the introduction and results sections. ES conducted and ADD oversaw the Cochrane review embedded in this paper. All authors contributed to and approved the final draft of the paper. We gratefully acknowledge the Cochrane Dementia Group for their 
assistance in conducting the systematic search. ADD was Principal Investigator and RU co-investigator of the Older People And n-3 Long-chain polyunsaturated fatty acid (OPAL) trial included in this review. VAA led the analysis and writing of the cognitive outcome paper from the SU.FOL.OM3 trial included in this review. This research received no specific grant from any funding agency in the public, commercial or not-for-profit sectors. All authors state that there are no conflicts of interest.

\section{References}

1. Cunnane SC, Plourde M, Pifferi F, et al. (2009) Fish, docosahexaenoic acid and Alzheimer's disease. Prog Lipid Res 48, 239-256.

2. Fotuhi M, Mohassel P \& Yaffe K (2009) Fish consumption, long-chain omega-3 fatty acids and risk of cognitive decline or Alzheimer disease: a complex association. Nat Clin Pract Neurol 5, 140-152.

3. Huang TL (2010) Omega-3 fatty acids, cognitive decline, and Alzheimer's disease: a critical review and evaluation of the literature. J Alzheimers Dis 21, 673-690.

4. Kidd PM (2007) Omega-3 DHA and EPA for cognition, behavior, and mood: clinical findings and structural-functional synergies with cell membrane phospholipids. Altern Med Rev 12, 207-227.

5. Morris MC (2009) The role of nutrition in Alzheimer's disease: epidemiological evidence. Eur J Neurol ;16 Suppl 1, $1-7$.

6. Robinson JG, Ijioma N \& Harris W (2010) Omega-3 fatty acids and cognitive function in women. Womens Health (Lond Engl) 6, 119-134.

7. Solfrizzi V, Frisardi V, Capurso C, et al. (2010) Dietary fatty acids in dementia and predementia syndromes: epidemiological evidence and possible underlying mechanisms. Ageing Res Rev 9, 184-199.

8. Uauy R \& Dangour AD (2006) Nutrition in brain development and aging: role of essential fatty acids. Nutr Rev S24-33, 64, S72-S91.

9. Albanese E, Dangour AD, Uauy R, et al. (2009) Dietary fish and meat intake and dementia in Latin America, China, and India: a 10/66 Dementia Research Group populationbased study. Am J Clin Nutr 90, 392-400.

10. Nurk E, Drevon CA, Refsum H, et al. (2007) Cognitive performance among the elderly and dietary fish intake: the Hordaland Health Study. Am J Clin Nutr 86, 1470-1478.

11. Dangour AD, Allen E, Elbourne D, et al. (2009) Fish consumption and cognitive function among older people in the UK: baseline data from the OPAL study. $J$ Nutr Health Aging 13, 198-202.

12. van de Rest O, Spiro A 3rd, Krall-Kaye E, et al. (2009) Intakes of (n-3) fatty acids and fatty fish are not associated with cognitive performance and 6-year cognitive change in men participating in the Veterans Affairs Normative Aging Study. J Nutr 139, 2329-2336.

13. Cherubini A, Andres-Lacueva C, Martin A, et al. (2007) Low plasma N-3 fatty acids and dementia in older persons: the InCHIANTI study. J Gerontol A Biol Sci Med Sci 62, $1120-1126$

14. Samieri C, Feart C, Proust-Lima C, et al. (2010) Omega-3 fatty acids and cognitive decline: modulation by ApoEepsilon 4 allele and depression. Neurobiol Aging.

15. Schaefer EJ, Bongard V, Beiser AS, et al. (2006) Plasma phosphatidylcholine docosahexaenoic acid content and risk of dementia and Alzheimer disease: the Framingham Heart Study. Arch Neurol 63, 1545-1550.

16. Laurin D, Verreault R, Lindsay J, et al. (2003) Omega-3 fatty acids and risk of cognitive impairment and dementia J Alzheimers Dis 5, 315-322.

17. Barberger-Gateau P, Letenneur L, Deschamps V, et al. (2002) Fish, meat, and risk of dementia: cohort study. Bmj $\mathbf{3 2 5}$ 932-933.

18. Morris MC, Evans DA, Bienias JL, et al. (2003) Consumption of fish and n-3 fatty acids and risk of incident Alzheimer disease. Arch Neurol 60, 940-946.

19. van Gelder BM, Tijhuis M, Kalmijn S, et al. (2007) Fish consumption, n-3 fatty acids, and subsequent 5-y cognitive decline in elderly men: the Zutphen Elderly Study. Am J Clin Nutr 85, 1142-1147.

20. Devore EE, Grodstein F, van Rooij FJ, et al. (2009) Dietary intake of fish and omega-3 fatty acids in relation to longterm dementia risk. Am J Clin Nutr 90, 170-176.

21. Kesse-Guyot E, Peneau S, Ferry M, et al. (2011) Thirteen-year prospective study between fish consumption, long-chain n-3 fatty acids intakes and cognitive function. $J$ Nutr Health Aging 15, 115-120.

22. Lim WS, Gammack JK, Van Niekerk J, et al. (2006) Omega 3 fatty acid for the prevention of dementia. Cochrane Database Syst Rev CD005379.

23. Sydenham E, Dangour AD \& Lim WS Omega 3 fatty acids for the prevention of cognitive decline and dementia. Cochrane Database Syst Rev, CD005379 (in press).

24. Dangour AD, Allen E, Elbourne D, et al. (2010) Effect of 2-y n-3 long-chain polyunsaturated fatty acid supplementation on cognitive function in older people: a randomized, double-blind, controlled trial. Am J Clin Nutr 91, $1725-1732$

25. Geleijnse JM, Giltay EJ \& Kromhout D (2011) Effects of n-3 fatty acids on cognitive decline: A randomized, doubleblind, placebo-controlled trial in stable myocardial infarction patients. Alzheimers Dement. http://dx.doi.org/10.1016/ j.jalz.2011.06.002

26. van de Rest O, Geleijnse JM, Kok FJ, et al. (2008) Effect of fish oil on cognitive performance in older subjects: a randomized, controlled trial. Neurology 71, 430-438.

27. Andreeva VA, Kesse-Guyot E, Barberger-Gateau P, et al. (2011) Cognitive function after supplementation with B vitamins and long-chain omega- 3 fatty acids: ancillary findings from the SU.FOL.OM3 randomized trial. Am J Clin Nutr 94, 278-286.

28. Yurko-Mauro K, McCarthy D, Rom D, et al. (2010) Beneficial effects of docosahexaenoic acid on cognition in age-related cognitive decline. Alzheimers Dement 6, 456-464.

29. Freund-Levi Y, Eriksdotter-Jonhagen M, Cederholm T, et al. (2006) Omega-3 fatty acid treatment in 174 patients with mild to moderate Alzheimer disease: OmegAD study: a randomized double-blind trial. Arch Neurol 63, 1402-1408.

30. Quinn JF, Raman R, Thomas RG, et al. (2010) Docosahexaenoic acid supplementation and cognitive decline in Alzheimer disease: a randomized trial. Jama $\mathbf{3 0 4}$, 1903-1911.

31. Kromhout D, Giltay EJ \& Geleijnse JM (2010) n-3 fatty acids and cardiovascular events after myocardial infarction. $N$ Engl J Med 363, 2015-2026.

32. Calon F, Lim GP, Yang F, et al. (2004) Docosahexaenoic acid protects from dendritic pathology in an Alzheimer's disease mouse model. Neuron 43, 633-645.

33. Rojas CV, Martinez JI, Flores I, et al. (2003) Gene expression analysis in human fetal retinal explants treated with 
docosahexaenoic acid. Invest Ophthalmol Vis Sci $\mathbf{4 4}$ $3170-3177$.

34. Bazan NG (2006) Cell survival matters: docosahexaenoic acid signaling, neuroprotection and photoreceptors. Trends Neurosci 29, 263-271.

35. Cole GM \& Frautschy SA (2010) DHA may prevent agerelated dementia. J Nutr 140, 869-874.

36. United Nations Food and Agriculture Organisation (2010) Fats and fatty acids in buman nutrition: report of an expert consultation. FAO Food and Nutrition Paper 91. Rome: FAO.
37. Elmadfa I \& Kornsteiner M (2009) Dietary fat intake-a global perspective. Ann Nutr Metab 54, Suppl. 1, 8-14.

38. Lawlor DA, Davey Smith G, Kundu D, et al. (2004) Those confounded vitamins: what can we learn from the differences between observational versus randomised trial evidence? Lancet 363, 1724-1727.

39. Dangour AD, Allen E, Richards M, et al. (2010) Design considerations in long-term intervention studies for the prevention of cognitive decline or dementia. Nutr Rev 68 , Suppl. 1, S16-S21. 